\title{
An Instrument for Dimensional Diagnosis of a Child Constitution (ICC) Individualizing the Care for Children with Developmental Disorders
}

\author{
Niemeijer $\mathrm{MH}^{1,2 *}$, Baars EW ${ }^{1}$, Hoekman ${ }^{3}$ and Ruijssenaars AJJM ${ }^{4}$ \\ ${ }^{1}$ University of Applied Sciences, Leiden, Netherland \\ ${ }^{2}$ Kingfisher Group, Louis Bolk Instituut, Netherland \\ ${ }^{3}$ Leiden University, Netherland \\ ${ }^{4}$ Groningen University, Netherland
}

Submission: July 26, 2017; Published: August 28, 2018

*Corresponding author: Martin Niemeijer, Hogeschool Leiden, Anthroposophical Health Care Research Group, Zernikedreef 11, 2333CK Leiden, Nederland; Email: mhn@planet.nl

Abstract

Objectives: Developmental disorders present themselves with complex problems that may threaten the child's development. In every child a disorder shows itself in a unique way, which makes it necessary to individualize. The objective of this study is to develop an instrument that provides a dimensional diagnosis by mapping the degree of (dis) balance on three domains of child development. The instrument is based on an anthroposophic anthropology and typology. Materials and methods: The typology of the child's constitution is operationalized using concept mapping en consensus building with experts. In a pilot study the psychometric properties of the instrument were preliminary tested on children with developmental disorders in Dutch institutions.

Results: The Instrument for diagnosis of a Child Constitution (ICC) consists of two parts. Part I contains 36 polar items in three subscales of 12 items, and is completed by healthcare professionals. Part II consists of three Visual analogue scales (VAS-scales and is completed by a practitioner. The outcome (the scores of Part I and II) is a profile of the child's constitution, showing the (dis)balance on three domains of child development. A pilot study with 38 children demonstrates positive face validity, and moderate internal consistency and inter-rater reliability of the ICC.

Conclusion: The ICC has been developed as a diagnostic instrument to assess individualized dimensional diagnosis of children with a developmental disorder. Future studies will focus on validation of the instrument.

Keywords: Dimensional Diagnosis; Child Constitution; Developmental Disorders; Anthroposophic anthropology; Typology; ICC; Tacit knowledge

Abbreviations: ASD: Autism Spectrum Disorder; ADHD: Attention Deficit Hyperactivity Disorder; COSMIN: Consensus-based Standards for selection of health Measurement Instruments; McDD: Multicomplex Developmental Disorder

\section{Introduction}

\section{Developmental disorders}

Developmental disorders include a broad range of psychological and physical symptoms through which children differ from what is generally considered as normal. These neurodevelopmental disorders [1] have a pervasive effect on the child's development; they may affect it permanently in multiple developmental domains. The following disorders are mostly included: language/speech, learning and motoric disorders, Autism Spectrum Disorder (ASD), Attention Deficit Hyperactivity Disorder (ADHD), Obsessive Compulsive Disorder, Conduct Disorder and tic disorders. Also, intellectual disabilities and genetic syndromes, like Down's syndrome. There are clinicians who also consider early traumatic experiences that affect the development of the child's capacity to build attachments with others as a developmental disorder [2].

The prevalence of developmental disorders seems to be increasing. In American research amongst children between the ages of 3 and 17, Boyle et al. [3] found an increase in the prevalence from $12.84 \%$ to $15.04 \%$ between the periods $1997 / 1999$ to $2006 / 2008$. In this study ADHD, ASD, learning disorders, sensory disorders, intellectual disabilities, epilepsy and motoric disorders were included. The prevalence of ASD increased from $0.19 \%$ to $0.74 \%$ in the aforementioned period, ADHD from $5.69 \%$ to $7.57 \%$ [3].

Developmental disorders rarely occur in isolation. Often there is comorbidity, such learning disorders and ASD [4]. More 
than $70 \%$ of the children with ASD have at least one comorbid disorder [5] and 40\% have two or more [6].

Kaplan [7] considers the term 'comorbidity' of limited value in relation to developmental disorders; they are atypical and neurological dysfunctions that lead to a continuum of disorders. In each child a developmental disorder has an unique presentation. In the DSM-5 [8], the categorical structure does not always fit the realities of clinical practice and scientific research. Therefore, steps in a more dimensional approach and individualization in diagnosis is to be preferred.

\section{Diagnostics}

Theories relating to developmental disorders are multidisciplinary, with contributions from the field of developmental psychology [9] and medicine [10]. This links well with an interdisciplinary approach in the examination and diagnosing of children with a possible developmental disorder [11]. This way of diagnosing consists of the classification of the disorder and mapping out the child's individual functioning.

Classifying disorders in well-defined categories has led to the development of protocol and evidence-based treatments for similar problems [12]. A disadvantage of the categorical classification is the often all-or-nothing threshold concerning the number of criteria that must be adhered to in order to establish the presence of a disorder [13]. Developmental disorders manifest themselves in varying degrees in different developmental domains [14]. The alignment with the individual's situation is achieved more effectively in a dimensional approach $[15,16]$.

\section{Constitutional diagnostics}

In the anthroposophical inspired care for children with a developmental disorder determining the constitution is a method to map out the child's individual situation [17]. This method in health care has derived from a typology of the constitution, which has its basis in the anthroposophic anthropology [18-20].

The concept of 'type' used here can be characterized as a dynamic and plastic complex of ways to constitute similar but not identical living organisms [21]. The type functions as the active designer, which expresses itself in form and function of an organism and organs. For living nature the type is what laws of nature, like gravity, are for the dead nature. As such, the type is invisible to the physical senses. It does apply to the individual organisms that are manifestations of a type. Every living $\operatorname{organ}(i s m)$ is an unique manifestation of a type. In the typology of the constitution three organs as domains of development in the child's functioning are distinguished, a cognitive, an affective and a conative domain. In these domains the typology focuses on a designer, a type. This type constitutes in each domain biopsychosocial processes of

development, with on both extremes of a continuum a polar pair of one-sidedness. In the constitutional diagnostics of a child the degree of (im-)balance on the continuum in these domains is identified [19].
On the continuum in the domain of cognitive functioning the quality of perception and thinking are central. On the one hand, this consists of the capacity to bring form and congruency in perceptions, as well as in thoughts and memories. On the other hand, it consists of the capacity to let go of these thoughts and to forget them. The domain of affective functioning is concerned with the experience and expression of feelings and emotions and the ability to pull back and close oneself off from the environment. The domain of conative functioning is centered on movement and mobility. The capacity to slow down and be passive and on the other hand to move and be active.

The child's functioning can be registered on a continuum for each of these domains, with sidedness on either sides of a healthy middle area. In the three developmental domains, the six constitutional images represent that sidedness. The names that characterise the six images consist of a verb and a noun:

a) Densifying/Obsessive versus Dissolving/Forgetful for the cognitive developmental domain

b) Closing/Clenched versus Opening/Outflowing for the affective developmental domain

c) Decelerating/Heavy versus Accelerating/Light for the conative developmental domain

Each child has its own degree of (im-)balance in the continuums of the three developmental domains, which defines its constitution.

\section{Theoretical framework}

The child's development occurs as a transactional process [9] in a continuous exchange between the organism and the environment; both of which are continuously changing $[22,23]$. A developmental disorder intervenes in this interaction. For adaptation and recovering of balance in functioning, the child's organism uses self-regulating capacities, such as resilience [24].

Recognising these capacities is linked to attitudes regarding health as a dynamic phenomenon, as the capacity to adapt and maintain autonomy in light of physical, emotional and social challenges [25]. The typology of the constitution is built on this concept of health. The three developmental domains that are used in this typology - the cognitive, affective and conative domains - are known from psychology $[26,27]$ and psychiatric research $[28,29]$.

The term 'constitution typology' refers to the basis of constitutional characteristics. In the literature, the term 'constitution' is used as a reference to predisposition, the genetic constitution of the child. The genetic constitution is responsible for the development of structure and functions of an organism [30]. In this meaning, constitution is usually an immutable, static fact of the child's predisposition. However, in the constitution typology, the constitution is a dynamic phenomena. The child's constitution changes during lifetime under the influence of the environment and the child's own personality. As a result, this meaning of constitution is influencable through treatment. 
As an indicator of the coherence between predisposition and bio-psychosocial phenomena the term constitution seems to be losing its meaning, in favour of the term 'temperament'. This appears from the description of temperament as predispositionbased individual differences in behaviour [31]. Temperament consists of personality characteristics that have a genetic and neurobiological foundation [32]. There are similarities and differences between the meaning and role of 'constitution' and 'temperament' in the literature. A similarity is that in the constitutional images, constitution refers to coherence in predisposition and bio-psychosocial processes; comparable to temperament $[18,19,33]$. A difference is the relation to developmental disorders. Temperament is considered to be a personality factor that protects the child, or constitutes a risk factor for the development of disorders [34]. The used meaning of constitution here consists of the actual bio-psychosocial functioning of the child, including a possible developmental disorder.

\section{Aim and research questions}

The aim of this study is developing a measuring instrument to determine the degree of (im-)balance in the child's constitution. This study supports the scientific basis of Integrative Healthcare [35] and in particular, anthroposophical inspired healthcare [36]. The study is societally relevant because it contributes to the further development of an anthroposophic healthcare that is focused on the situation of the individual child and its environment. Previous steps in the scientific justification are a methodical description of the healthcare [17] and the typology of the constitution $[19,20,37]$.

The questions of this study are:

a) Which bio-psychosocial phenomena should be included in the instrument?

b) Which design of the instrument fits best the constitutional typology?

c) What are the outcomes of the investigation into internal consistancy, inter- and intra-rater

d) reliability?

\section{Methods}

To answer the first question, concept mapping has been used in a group of experienced professionals. We used consensus building to determine which items should be included and how the instrument should be designed. For the third question, a pilot study was conducted with the cooperation of practitioners. A questionnaire was filled out to determine instrumental usability.

\section{Concept mapping}

Concept mapping is used for the operationalisation of concepts in (healthcare-based) research [38]. It entails the generation, prioritisation and clustering of phenomena, which, through a cluster analysis, leads to an overview of the attitudes of the group of people in question [39]. In this study, we worked with the written variant of concept mapping [40] in order to generate, prioritise and cluster the concerning characterising bio-psychosocial phenomena for the first research question. For this analysis we used the Ariadne programme ${ }^{1}$, which combines statistical techniques, Principal Components Analysis and Hierarchical cluster analysis.

Experienced professionals: Experienced professionals can be considered the carriers of 'tacit knowledge' [41]. A total of 42 people were asked to participate in this study (12 professional supervisors, six artistic therapists, 11 remedial educationalists / psychologists and 13 doctors). Of these 42,14 people opted out of the study (ill, no time) and six people did not response. The remaining group of 22 experienced professionals consists of three professional supervisors, four therapists, eight remedial educationalist/psychologists and seven doctors. Their average number of years of experience in healthcare was 16.2 years (range: 6.4 - 21.3).

Two rounds of questionnaires: The 22 participants received a questionnaire in two rounds. All of the participants (100\%) responded to the first questionnaire; the second questionnaire had a response rate of $63.6 \%$ (14 participants). In the first round the participants were asked which bio-psychosocial phenomena they consider typical for each constitutional domain on the basis of their expertise. In the second round, the participants were asked to prioritise the gathered phenomena from the first round. In addition, they were asked to categorise the connected phenomena in clusters. Prioritisation could be given on a fivepoint scale, ranging from low (1) to high (5) ${ }^{2}$. The phenomena with an average prioritisation higher than 3.5 were considered important for the diagnostics of the constitution.

\section{Consensus building}

Consensus is the agreement regarding a matter by experts, in light of the actual situation of the empirical study and their shared professional experience, and in words that mean the same to the discussion partners [42].

In three meetings with the experienced professionals and researchers, consensus building took place between the professionals and researchers to answer the second and third question, relating to the composition and design of the instrument.

\section{Design of the instrument}

In the consensus group, the researchers put forward a proposition for the construction of the instrument. In this proposal, the principle of polarity was applied and the constitution was made measurable in two ways. We chose to use

${ }^{1}$ Ariadne is a computer program for Concept Mapping that was designed and written by Talcott BV. The Dutch centre for Geestelijke Volksgezondheid (Mental Public Health) made this method usable for research in the Netherlands in 1995.

${ }^{2} 1$ = least important; 2 = a little important; 3 = somewhat important; 4 = relatively important; $5=$ most important; $9=$ no opinion 
measuring scales, through which the degree of (im-) balance in a system could be scored.

The first way of measuring the constitution consists of judging polar-formulated phenomena on a seven-point Likert scale, with a range from -3 to +3 . With this, it is indicated whether there is a balance, and if so/or not, to what extent there is or is not a balance disruption in each of the polar-formulated items. The score 0 points towards a balance; all other scores indicate a greater or lesser deviation from this balance. This way of measuring has an analytical character; the child's scores are determined on the basis of separate phenomena.

The second way of measuring consists of the clinical evaluation by the practitioner, regarding the degree of balance, or one-sidedness, in each of the three pairs of the polar phenomena. By comparing the image of the child as it appeared in the diagnostic investigation with a characterising description of the three pairs of polar phenomena, an experienced professional can determine how the image that she/he developed of the child relates to this. In the instrument he can indicate this assessment on three Visual Analogue Scales (VAS scales). The measuring of VAS scales appeals to the practitioner's tacit knowledge [41] and the capacity to recognise a pattern or 'Gestalt' [43] and is connected to the method of 'pattern recognition' [17,44].

\section{Pilot study}

To answer the third question, through a pilot study with 38 children, the instrument was investigated in terms of internal consistency, inter-rater reliability and instrumental usefulness. Fifteen practitioners, six doctors and nine remedial educationalists/psychologists cooperated in this pilot study. For each of the 38 children, the instrument was filled out; the polar-formulated items separately by two professional supervisors and the VAS scale separately by two practitioners, a remedial educationalists/psychologist and a doctor. The child's practitioner filled out the requested personal information: initials, date of birth and gender, the actual DSM classification and determined level of functioning through an intelligence investigation of the child, the date of entry and the practitioner's own name and job position.

The internal consistency of the instrument of the three subscales was determined by establishing Cronbach's alpha. The inter-rater reliability was determined by calculating the Pearson correlations of unweighted sum scores, between pairs of evaluators for each of the three subscales in Part I and the three VAS scales in Part II. The Consensus-based Standards for selection of health Measurement Instruments (COSMIN) [45], gave as a criterion for the quality of the internal consistency a Cronbach's alpha of $>.70$ and a Pearson correlation of $>.70$ for the inter-rated reliability. The instrumental usefulness was investigated with an inventory of the experience of respondents using the instrument, and through the determination of the missing values, whereby a maximum percentage of $5 \%$ was established [46].

\section{Results}

\section{Concept mapping}

Creation the inventory and prioritization: The number of phenomena, which were generated by the experience experts in the first questionnaire and received an average prioritisation equal to or greater than 3.5 on the five-point scale in the second round, were the following for the polar phenomena:

a) Densifying/Obsessive - Dissolving/Forgetful: in the first round: 38 and 36; and in the second round: $(46.6 \%$ of the number generated in the first round) and 17 (47.2\%);

b) Closing/Clenched - Opening/Outflowing: 60 and 59 in the first round; in the second round: 34 (56.6\%) and 26 (44.1\%);

c) Decelerating/Heavy - Accelerating/Light: 40 and 60 in the first round; in the second round: 17 (42.5\%) and 29 (48.3\%).

Clustering: The phenomena, which were clustered and prioritised by the separate participants, were processed into an average clustering in the Ariadne programme, using the Principal Components Analysis and Hierarchical cluster analysis. The choice for two clusters presented the best options for interpretation, and with that, an organising principle for the selection of the items to be included in the instrument. The first cluster contains psychological phenomena and the second cluster consists of biological/physiological phenomena in their related developmental domains.

\section{Consensus building}

In the consensus discussions with the experience experts, an agreement was reached regarding the researchers' proposition relating to the construction and design of the instrument, as described in the section Methods. The Instrument for the determination of the Child's Constitution (ICC) consists of two parts. Part I contains 36 polar-formulated items, for the assessment on a seven-point Likert scale. Part II contains three VAS scales, which indicate the degree of balance or imbalance in the developmental domains. For Part I of the ICC, the number of items for each of the three developmental domains is maximised at 12 . Items have been selected from the two clusters of phenomena, with a minimum of two items per cluster. The selection of the items took place on the basis of the ranking according to the prioritisation. For Densifying/ Obsessive versus Dissolving/Forgetful, ten items from the first cluster were selected, and two items from the second cluster. For both the Closing/Clenched versus Opening/Outflowing and the Decelerating/Heavy versus Accelerating/Light polarities, nine items were selected from the first cluster and three items from the second cluster.

In the explanation with the ICC it is indicated that for the filling out of the child's functioning, the month prior to the moment of entry should be considered leading. Part I of the ICC is filled out by people who are professionally involved in 
the care of the child. Part II is filled out by the diagnostically responsible practitioner. For the filling out of Part II of the ICC, a characterising description of the three constitutional types have been formulated in clarifying notes, as a support for the filling out of the VAS scales.

\section{Pilot study}

Composition study group: The ICC was used for the diagnostics of 38 children/adolescents; 10 girls and 28 boys. Their average age was 10.0 years (range: 7 - 16). Of these children, 14 were classified as having a disorder in the Autistic Spectrum, six had Multicomplex Developmental Disorder (McDD), five ADHD, three an Attachment disorder and one child had Down's syndrome. The nine other children were diagnosed with an intellectual disability.

The children's level of functioning varied from averagely gifted (five children) to severely mentally disabled (one child); 17 children functioned at a moderately mentally retarded level, 11 children had a slight mental disability and four children had a moderate mental disability. Of the children and adolescents, seven were in day-care treatment; the remaining 31 were receiving clinical treatment.

Internal consistency: Cronbach's alpha for Part I in its entirety is .79. For the three subscales of Part I, Cronbach's alpha is .64 (Closing/Clenched-Opening/Outflowing); .67 (Densifying/ Obsessive-Dissolving/Forgetful); and .76 (Decelerating/HeavyAccelerating/Light).

\section{Inter-rater reliability}

The Pearson correlations for the subscales of Part I was significant: ${ }^{* *} \mathrm{p}<.01$ :

\section{a) Densifying/Obsessive - Dissolving/Forgetful .66** \\ b) Closing/Clenched - Opening/Outflowing .69** \\ c) Decelerating/Heavy - Accelerating/Light .82**}

The Pearson correlations for the three VAS scales of Part II:

a) Densifying/Obsessive - Dissolving/Forgetful .44**

b) Closing/Clenched - Opening/Outflowing .25

c) Decelerating/Heavy - Accelerating/Light .47

Instrumental usefulness: The number of missing values in the 76 filled-out instruments was 45. In Part I of the instrument, 42 missing values were counted, spread over 19 of the 36 items. In Part II, the VAS scales, there were 3 missing values. In total, there were 45 missing values for 76 (number of filled out instruments: 38 children x 2) x 39 (number of items: 36 in Part I + 3 in Part II) $=2.964$ items; a percentage of $1.51 \%$.

The practitioners and supervisors indicated that the seven-point Likert scale in Part I provided sufficient room for nuancing in the answering of the questions. A few questions could not be responded to by all supervisors on the basis of their personal experience. This applied to questions regarding physical functioning, which were intended for the supervisors working in the day care treatment and artistic therapists. None of the practitioners added any remarks in the characterising description of the types in the Clarification of Part II of the instrument.

The following modifications were made to the instrument following the findings relating to the instrumental usefulness: four body-oriented items in Part I of the instrument, which had not been filled out by all supervisors, were made optional.

\section{Discussion}

This study concerns the development of the Instrument for the determination of the Child's Constitution (ICC) for the dimensional diagnostics of children with a developmental disorder. The selection of items for the instrument was established through concept mapping and consensus building with 22 experience experts with an average of 16.2 years of working experience in healthcare. This has resulted in an instrument that consists of three developmental domains and two sections. Part I contains 12 polar-formulated items for each of the three domains and is filled out by professional supervisors. Part II has a VAS scale for each of the three domains and displays the clinical evaluation of the practitioner responsible for the child's diagnosis. In a pilot study with 38 children/ adolescents, the internal consistency, the inter-rater reliability and instrumental usefulness were exploratively investigated. Cronbach's alpha is good for the entire instrument (.79) and 'mediocre' to 'good' for the three subscales of Part I (.64 - . 76). The Pearson correlation for the inter-rated reliability of the three subscales of Part I ranges between .66 and .82; all three are significant $(\mathrm{p}<.01)$. For the three VAS scales in Part II, the correlations are low; in the .25 to .47 range. Except the subscale Closing/Clenched - Opening/Outflowing, these are statistically significant $(\mathrm{p}<.01)$. Investigation into the instrumental usability has led to modification of the instrument: four items in Part I of the instrument were made optional. These are body-oriented biological/physiological items, which cannot be filled out by all supervisors, as shown by the number of missing values per item. The number of missing values remains far below the set maximum of $5 \%$ with a percentage of $1.51 \%$. All 36 items of Section I are maintained.

A first limitation of the study is that the constitutional approach is founded on the anthroposophic anthropology, of which the philosophical and empirical justification of the theoretical framework are still developing [39]. A second limitation concerns the quality of the pilot study into the validity and reliability of the developed instrument. The study group is small and not randomly composed, nor have all aspects of validity and reliability been tested. 


\section{Conclusion}

Nonetheless, the ICC in this phase of its development is already of importance to anthroposophic daily practice. It provides handles for the individualisation of the diagnostics and for individual choices in child-oriented treatments. Additionally, it contributes to the explication and operationalisation of anthroposophic concepts, and by doing so, to further scientific support base of anthroposophic-inspired healthcare. Generally speaking, the construction of the ICC with the polar-formulated items is an example of a questionnaire which is based on a dynamic healthcare concept.

Subsequent steps that will be taken in the developmental process of the instrument are:

improvement of the manual of the use of the instrument, research into the reliability, validity and responsiveness of the instrument, and further theoretical justification of the constitutional approach towards healthcare.

\section{Referencers}

1. American Psychiatric Association (2013) Diagnostic and Statistical Manual of Mental Disorders (DSM-5®). American Psychiatric Pub.

2. Van der Kolk BA (2005) Developmental Trauma Disorder. In: Psychiatric Annals. Psychology Module 35(5): 401-408.

3. Boyle CA, Boulet S, Schieve LA, Cohen RA, Blumberg SJ, et al. (2011) Trends in the prevalence of developmental disabilities in US children, 1997-2008. Pediatrics, 127(6): 1034-1042.

4. Kaplan B, Crawford S, Cantell M, Kooistra L, Dewey D (2006) Comorbidity, cooccurrence, continuum: What's in a name? Child Care Health and Development, 32(6): 723-731.

5. Simonoff E, Pickles A, Charman T, Chandler S, Loucas T, Baird G (2008) Psychiatric disorders in children with autism spectrum disorders: prevalence, comorbidity, and associated factors in a population-derived sample. Journal of the American Academy of Child \& Adolescent Psychiatry 47(8): 921-929.

6. Matson JL, Nebel-Schwalm MS (2007) Comorbid psychopathology with autism spectrum disorder in children: An overview. Research in developmental disabilities 28(4): 341-352.

7. Kaplan BJ, Dewey DM, Crawford SG, Wilson BN (2001) The Term Comorbidity Is of Questionable Value in Reference to Developmental Disorders Data and Theory. Journal of learning disabilities, 34(6): 555565 .

8. American Psychiatric Association (2013) Diagnostic and Statistical Manual of Mental Disorders (DSM-5®). American Psychiatric Pub.

9. Pennington BF (2006) From single to multiple deficit models of developmental disorders. Cognition, 101(2): 385-413.

10. Morton J (2008) Understanding developmental disorders: A causal modelling approach. Oxford: Blackwell publishers.

11. Verhulst FC, Verheij F (2009) Kinder- en Jeugdpsychiatrie, Onderzoek en diagnostiek. Assen: Van Gorcum.

12. Braet C, Bögels SM (2013) Protocollaire behandelingen voor kinderen enadolescenten met psychische klachten. Amsterdam: Boom.

13. Jongedijk RA (2001) Psychiatrische diagnostiek en het DSM-systeem. Tijdschrift voor psychiatrie 43(5): 309-320.

14. Rutter M (2011) Research review: Child psychiatric diagnosis and classification: concepts, findings, challenges and potential. Journal of Child Psychology and Psychiatry 52(6): 647-660.
15. Hudziak JJ, Achenbach TM, Althoff RR, Pine DS (2007) A dimensional approach to developmental psychopathology. International journal of methods in psychiatric research 16(S1): S16-S23.

16. Ruijssenaars AJJM, van den Bergh PM, van Drenth JML (2012) Orthopedagogiek. Ontwikkelingen, theorieën en modellen. Antwerpen/ Apeldoorn: Garant.

17. Baars E (2005) Goede zorg: een antroposofische benadering van ethische uitgangspunten en methodische aspecten van goede zorg. Zeist: Christofoor.

18. Steiner R (1924) Heilpädagogischer Kurs. Dornach: Rudolf Steiner Taschenbücher aus dem Gesamtwerk.

19. Niemeijer MH, Gastkemper M (2009) Ontwikkelingsstoornissen bij kinderen. Assen: Van Gorcum.

20. Göschel JC (2012) Der biografische Mythos als pädagogisches Leitbild. Dornach: Verlag am Goetheanum.

21. Van der Bie G (2012) Wholeness in Science. A methodology for pattern recognition and clinical intuition. From the series: Bolk's Fundamental Companions. Driebergen: Louis Bolk Instituut.

22. Sameroff A (2009) The transactional model. American Psychological Association.

23. Bronfenbrenner U, Morris PA (2006) The bioecological model of human development. Handbook of child psychology.

24. Luthar SS, Cicchetti D, Becker B (2000) The construct of resilience: A critical evaluation and guidelines for future work. Child development 71(3): 543-562.

25. Huber M, Knottnerus JA, Green L, Horst HVD, Jadad AR, et al. (2011) How should we define health? British Medical Journal 343: d4163.

26. Pervin LA, John OP (1999) Handbook of personality: Theory and research. Elsevier.

27. Dai DY, Sternberg RJ (2004) Motivation, emotion, and cognition: Integrative perspectives on intellectual functioning and development. Routledge.

28. Dennis M, Simic N, Bigler ED, Abildskov T, Agostino A, et al. (2013) Cognitive, affective, and conative theory of mind (ToM) in children with traumatic brain injury. Developmental cognitive neuroscience 5: 25-39.

29. Hengeveld MW, Schudel WJ (2004) Het psychiatrisch onderzoek (3de druk). Tijdschrift voor Psychiatrie 46(12): 823-824.

30. Siegel DJ (2012) The developing mind: How relationships and the brain interact to shape who we are. New York: Guilford Press.

31. Nigg JT (2006) Temperament and developmental psychopathology. Journal of Child Psychology and Psychiatry 47(3-4): 395-422.

32. Whittle S, Allen NB, Lubman DI, Yücel M (2006) The neurobiological basis of temperament: towards a better understanding of psychopathology. Neuroscience \& Biobehavioral Reviews 30(4): 511525 .

33. Niemeijer MH, Baars EW (2004) Beeldvormende diagnostiek van de kinderlijke constitutie. Driebergen: Louis Bolk Instituut.

34. De Pauw SS, Mervielde I (2010) Temperament, personality and developmental psychopathology: A review based on the conceptual dimensions underlying childhood traits. Child Psychiatry \& Human Development 41(3): 313-329.

35. Academic Consortium for Integrative Medicine \& Health (n.d.).

36. Kienle GS, Kiene H, Albonico HU (2006) Anthroposophic medicine: effectiveness, utility, costs, safety. Schattauer Verlag.

37. Grimm R, Kaschubowski G (2008) Kompendium der anthroposophischen Heilpädagogik. Basel: Reinhardt. 
38. Trochim WM (1989) An introduction to concept mapping for planning and evaluation. Evaluation and program planning 12(1): 1-16.

39. Swanborn PG (2007) Evalueren: het ontwerpen, begeleiden en evalueren van interventies: een methodische basis voor evaluatieonderzoek. Amsterdam: Boom.

40. Häder M, Häder S (2000) Die Delphi-Methode als Gegenstand methodischer Forschungen. In Die Delphi-Technik in den Sozialwissenschaften. VS: Verlag für Sozialwissenschaften. pp. 11-31.

41. Polanyi M (1997) Tacit knowledge. Knowledge in organisations 135146

42. Kaasenbrood A (1995) Consensus als criterium. De ontwikkeling, de verspreiding en het gebruik van richtlijnen voor goed psychiatrisch handelen. Utrecht: NcGv.

This work is licensed under Creative

Commons Attribution 4.0 License

DOI: 10.19080/JCMAH.2018.07.555717
43. Daston L, Galison P (2007) Objectivity. Brooklyn. NY: Zone Books.

44. Stolper E, Van de Wiel M, Van Royen P, Van Bokhoven M, Van der Weijden T, Dinant GJ (2011) Gut feelings as a third track in general practitioners' diagnostic reasoning. Journal of general internal medicine 26(2): 197 203.

45. Terwee CB, Bot SD, de Boer MR, van der Windt DA, Knol DL, et al. (2007) Quality criteria were proposed for measurement properties of health status questionnaires. Journal of clinical epidemiology 60(1): 34-42.

46. Schafer JL (1999) Multiple imputation: a primer. Statistical methods in medical research 8(1): 3-15.

\section{Your next submission with Juniper Publishers} will reach you the below assets

- Quality Editorial service

- Swift Peer Review

- Reprints availability

- E-prints Service

- Manuscript Podcast for convenient understanding

- Global attainment for your research

- Manuscript accessibility in different formats

(Pdf, E-pub, Full Text, Audio)

- Unceasing customer service

Track the below URL for one-step submission https://juniperpublishers.com/online-submission.php 